\title{
Raman study of doped-ZnO thin films grown by rf sputtering
}

\author{
M. F. Cerqueira, A. G. Rolo, T. Viseu, J. Ayres de Campos, T. de Lacerda-Arôso, F. Oliveira, \\ M. I. Vasilevskiy, E. Alves* \\ Centro de Física, Campus de Gualtar, Universidade do Minho, 4710-057 Braga, Portugal \\ * ITN, Ion Beam Laboratory, E. N. 10, 2686-953 Sacavém, Portugal
}

\section{Contact author: fcerqueira@ fisica.uminho.pt}

Keywords: $\mathrm{ZnO}$; doping; Raman scattering, phonons

\begin{abstract}
A Raman spectroscopy study of doped versus undoped $\mathrm{ZnO}$ layers is presented. The layers were grown by RF magnetron sputtering and the doping with $\mathrm{Al}, \mathrm{Sb}$ and $\mathrm{Mn}$ was achieved by ion implantation with subsequent annealing. First-order Raman response measured under $\lambda=488 \mathrm{~nm}$ excitation is discussed. It is shown that doping with any of the impurities used in this work produces a strong enhancement of the longitudinal optical (LO) phonon band, which is attributed to the intra-band Fröhlich mechanism. In addition, doping with $\mathrm{Mn}$ results in an extra mode located at $530 \mathrm{~cm}^{-1}$, tentatively attributed to a local vibrational mode of $\mathrm{Mn}$ substituting $\mathrm{Zn}$ in the lattice sites.
\end{abstract}

\section{Introduction}

The increased interest in $\mathrm{ZnO}$, in the form of thin films and nanostructure layers is due to their potential applications in a large variety of fields ranging from transparent electronics (requiring $n$ - and $p$-type conductive layers) to spintronics relying on the material doped with magnetic ions such as $\mathrm{Mn}$. To meet the demands of these applications, $\mathrm{ZnO}$ has to be doped with impurities such as $\mathrm{Ga}, \mathrm{Sb}, \mathrm{Al}, \mathrm{P}, \mathrm{Mn}$, in a controllable way. Raman spectroscopy is one of the most suitable techniques to assess the distribution of impurity atoms between different lattice sites and interstitial positions by probing the characteristic phonon modes of the material.

As known, $\mathrm{ZnO}$ crystal $(\mathrm{c}-\mathrm{ZnO})$ has the wurtzite structure with the point symmetry group $\mathrm{C}_{6 \mathrm{v}}$. The Raman-active phonon modes of c-ZnO are the non-polar ones of the E2 symmetry located at $101 \mathrm{~cm}^{-1}$ (E2 -low) and $437 \mathrm{~cm}^{-1}$ (E2 -high), the A1 and E1 transverse optical (TO) phonons, with the frequencies of $380 \mathrm{~cm}^{-1}$ and $407 \mathrm{~cm}^{-1}$, respectively, and the A1 and E1 longitudinal optical (LO) modes at, respectively, $574 \mathrm{~cm}^{-1}$ and $583 \mathrm{~cm}^{-1}$ [1]. In a back-scattering configuration, with the photon wave-vector 
parallel to the $c$-axis of the crystal (the configuration used in this work), only the E2 and A1(LO) modes are allowed by first-order Raman scattering selection rules.[2] Raman spectra of high quality singlecrystal undoped $\mathrm{ZnO}$ are in quite good correspondence with these selection rules [3]. However, despite the rather large number of studies reported, doubts still remain concerning the LO-modes $\left(500-600 \mathrm{~cm}^{-1}\right)$ of doped $\mathrm{ZnO}$ layers. Indeed, a not unique association between the wavenumber and the vibrational modes ZnO-based systems persists [2,4, 5, 6, 7]. In this work, experimental results of Raman spectroscopy of $\mathrm{Al}, \mathrm{Sb}$ and $\mathrm{Mn}$-doped $\mathrm{ZnO}$ layers, grown by $\mathrm{RF}$ magnetron sputtering and carefully characterized, are presented and discussed by focusing on the LO phonon spectral region (500-600 $\mathrm{cm}^{-1}$ ), in order to contribute to the non-ambiguous assignment of the observed Raman bands.

\section{Experimental}

Transparent $\mathrm{ZnO}$ layers were grown on glass substrates in an Alcatel SCM 650 sputtering system using a mixture of $\mathrm{O}_{2}$ and Ar gases (relative oxygen fraction of 0.23 ), at a constant working pressure of $0.7 \mathrm{~Pa}$ and at a substrate temperature of $50^{\circ} \mathrm{C}$. The target consisted of a hyper-pure (99.99\%) metal zinc wafer spaced $60 \mathrm{~mm}$ away from the substrates. Radio frequency $(13.56 \mathrm{MHz})$ reactive sputter deposition has been carried out after the camera had reached a base pressure of $5 \times 10^{-5} \mathrm{~Pa}$.

The as-grown films, which were $340 \mathrm{~nm}$ thick, were subsequently implanted with two different doses (D1 and D2) of Sb, Al and Mn ions using a high flux ion implanter (Danfysic model S1090). The implantation was performed following a Gaussian profile having its maximum at $100 \mathrm{~nm}$ in depth. For all doping ions, dose D1 corresponds to 1 at $\%$ and D2 to 3 at $\%$, as confirmed either by Rutherford backscattering spectrometry (RBS) - in the case of $\mathrm{Sb}$ and $\mathrm{Al}$ - or by particle induced X-ray emission analysis (PIXE) - in Mn ions. In order to recover from the implantation damage and to activate the implanted ions, samples were annealed at $500^{\circ} \mathrm{C}$ for $60 \mathrm{~min}$ in vacuum. Along with $\mathrm{ZnO}$ films doped with a single impurity, layers co-doped with $\mathrm{Al}$ and $\mathrm{Mn}$ were fabricated, hereafter referred to as $\mathrm{ZnO}: \mathrm{Al}: \mathrm{Mn}$. For these, equal doses (D1 and D2) of Mn were implanted into (previously characterized) $\mathrm{ZnO}$ :Al films. For comparison, we have also grown some $\mathrm{ZnO}: \mathrm{Mn}$ films by $\mathrm{RF}$ co-sputtering, which are called $\mathrm{ZnO}: \mathrm{Mn}(\mathrm{sp})$. The thickness of these sputtered films is $350 \mathrm{~nm}$.

All the produced samples have been analyzed by X-ray diffraction and optical transmittance spectroscopy at room temperature (RT). The micro-structure of the films has been analysed by X-ray diffraction and Raman scattering. X-ray experiments have been performed in a Philips PW 1710 diffractometer using $\mathrm{Cu}-\mathrm{K}_{\alpha}$ radiation, in a Bragg-Bretano geometry in the range $10^{\circ}<2 \theta<80^{\circ}$. Optical transmittance spectra of the films were measured using a Shimadzu UV 3101 PC spectrophotometer from 300 to $2500 \mathrm{~nm}$. 
Micro-Raman spectra were measured on a Jobin-Yvon T64000 spectrometer equipped with a liquid nitrogen cooled CCD detector, in the back-scattering geometry, in a frequency range of 200-700 $\mathrm{cm}^{-1}$, using the $488 \mathrm{~nm}(2.54 \mathrm{eV})$ excitation line of an $\mathrm{Ar}^{+}$laser with an incident power of $4 \mathrm{~mW}$.

\section{Results and discussion}

All the produced $\mathrm{ZnO}$ films are polycrystalline. This also holds for the implanted films after annealing. According to the X-ray diffraction spectra, the micro-crystallites have the wurtzite structure and show a strongly preferential orientation with the $c$-axis perpendicular to the surface, independently of the dopant ion and implantation dose. From the XRD analysis of the samples performed prior to implantation, the crystalline grain size has been estimated at $\approx 200 \AA$. After implantation, this size was found to decrease and then partially recovered with annealing, reaching a value some $10 \%$ lower than the initial one.

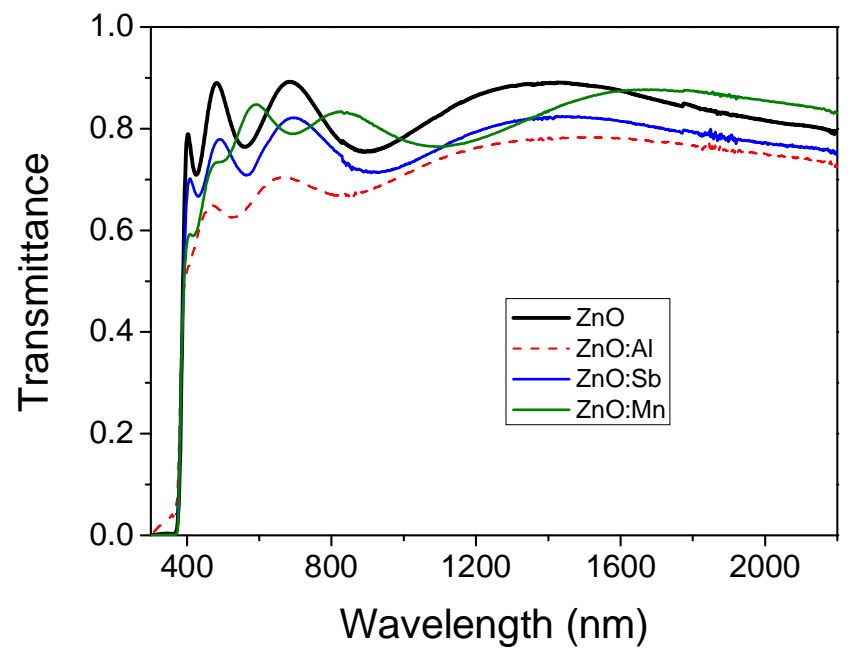

Figure 1: Transmission spectra of the undoped $\mathrm{ZnO}$ film and of the three films implanted with $\mathrm{D} 2$ dose (after annealing).

Figure 1 depicts typical transmission spectra of the films implanted with dose D2. For comparison it is also shown the transmission spectra of the corresponding undoped film. From the fits obtained by the Minkov method using the classical Lorentz-Drude theory for the dispersion of the complex dielectric function, the film thickness and optical parameters were determined [8]. After doping, the films remained transparent in the visible and NIR region revealing good optical quality (only the Mn-doped films exhibit its typical yellowish colour) regardless the implantation ion. However, we observed a small shift of the absorption edge with the increase of the dopant content, in agreement with ref [9]. The estimated optical band gap energy is in the range $3.2-3.3 \mathrm{eV}$. 
The essential Raman spectroscopy results are shown in Fig. 2. Figure 2a presents the Raman spectra of the original, non-doped $\mathrm{ZnO}$ thin film, and typical $\mathrm{Al}$ and $\mathrm{Sb}$-implanted $\mathrm{ZnO}$ thin films after the annealing treatment. In Fig. 2b, the spectra of $\mathrm{Mn}$-doped $\mathrm{ZnO}$ films prepared both by ion implantation ( $\mathrm{ZnO}: \mathrm{Mn}$ and $\mathrm{ZnO}: \mathrm{Al}: \mathrm{Mn})$ and co-sputtering ( $\mathrm{ZnO}: \mathrm{Mn}(\mathrm{sp}))$ are shown.
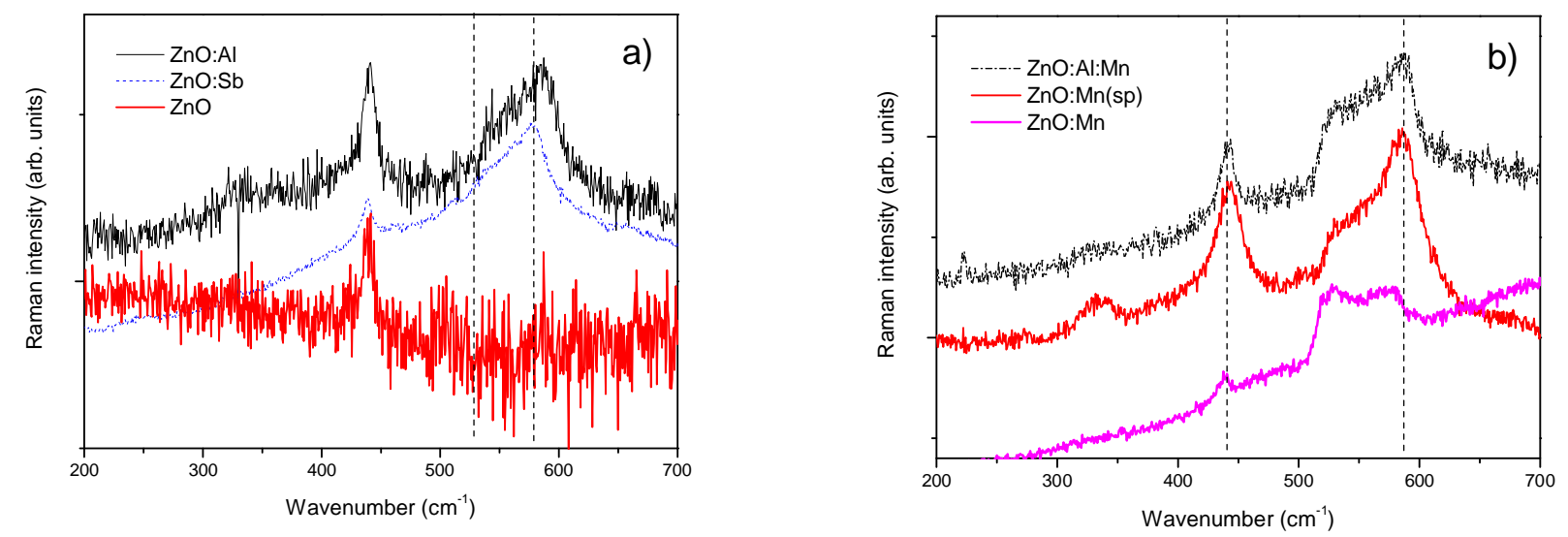

Figure 2: (a) Raman spectra of the original $\mathrm{ZnO}$ film and of those implanted with $\mathrm{Al}$ and $\mathrm{Sb}-\mathrm{ZnO}$ (the heaviest dose, i.e., dose D2) after annealing; (b) Raman spectra of the Mn-doped samples, $\mathrm{ZnO}: \mathrm{Mn}$ and $\mathrm{ZnO}: \mathrm{Al}: \mathrm{Mn}$ obtained by implantation, and $\mathrm{ZnO} \mathrm{Mn}(\mathrm{sp})$ produced by co-sputtering.

In the Raman spectrum of undoped $\mathrm{ZnO}$, only E2 (high) phonon mode is seen at $437 \mathrm{~cm}^{-1}$, as expected in the used geometry (backscattering with $k \| z$ ). Although the A1(LO) mode is also dipole-allowed in this geometry, for parallel polarizations of the incident and scattered light, in practice, it is hardly detectable. For instance, it was not observed for bulk c-ZnO unless under resonance excitation [10]. The low-intensity peak at $320 \mathrm{~cm}^{-1}$ seen for the undoped film and also in all the spectra presented in Figure 2 is assigned to a two-phonon-difference mode [3].

Doping with $\mathrm{Al}$ or $\mathrm{Sb}$ (Fig. 2a) results in the appearance of an intense and broad band in the spectral region close to the $\mathrm{LO}$ phonon frequencies of undoped c- $\mathrm{ZnO}\left(574 \mathrm{~cm}^{-1}\right.$ for A1-mode and $583 \mathrm{~cm}^{-1}$ for E1-mode) [11]. For $\mathrm{ZnO}: \mathrm{Sb}$ and $\mathrm{ZnO}: \mathrm{Al}$ samples, the maximum of this band (particularly intense for the $\mathrm{ZnO}: \mathrm{Sb}$ sample) lies at approximately $572 \mathrm{~cm}^{-1}$. It becomes more and more important with the increasing implantation dose, as it can be seen in Fig. 3 for $\mathrm{ZnO}$ :Sb samples. Similar effect has been observed in the literature for a number of doping impurities [1] and was attributed to point defects. However, the universal behavior of this band observed for $\mathrm{ZnO}$ doped with several impurities (also 
Mn, see Fig. 2b) hints that it may be related to LO-type lattice phonons. The enhancement of the LOphonon mode can be due to the intra-band Frohlich interaction. It is known that in III-V semiconductors, where LO-phonon scattering is dipole-forbidden, it is often seen under (or close to) resonant conditions. This mode is also strongly enhanced in nanostructures, e.g. QDs due to the (partial) separation of electron and hole clouds in space (created by the incident photon) [12]. Indeed, Raman spectra of "ZnO submicron crystals" presented in Ref. 6 are dominated by the LO phonon mode (in addition, the authors of this work used resonant excitation at $325 \mathrm{~nm}$ ). Probably something similar happens when the $\mathrm{ZnO}$ thin films are rather heavily doped, whatever the type of impurity ( $n$ or $p$ ) is. Then the strong scattering of the electrons and holes on the impurities can relax the $q=0$ selection rule of the dipole-allowed Raman scattering. One can also expect that LO phonons participating in the scattering will be a mixture of A1 and E1 modes because of the symmetry breaking introduced by the impurities. This may explain the slight shift of the peak position with doping.

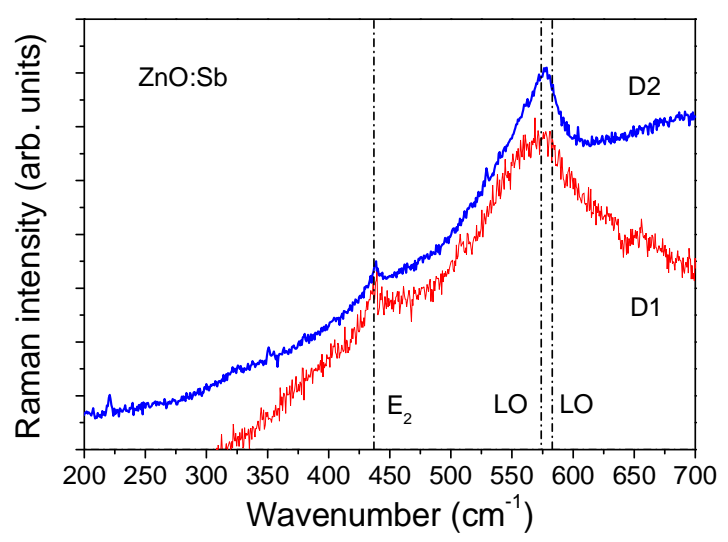

Figure 3: Raman spectra of two different doses of $\mathrm{ZnO}: \mathrm{Sb}$ thin films.

Doping $\mathrm{ZnO}$ with $\mathrm{Mn}$ introduces an extra mode at $\approx 530 \mathrm{~cm}^{-1}$ that appears in all Mn-doped spectra and is not observed for any other impurity. In order to clarify the origin of this mode, Raman spectroscopy was performed for $\mathrm{ZnO}: \mathrm{Mn}$ films implanted with two different doses, D1 and D2. The results are depicted in Fig. 4a and show that the intensity of the Raman signal at this frequency increases with increasing the concentration of Mn. In order to eliminate the possibility that this $530 \mathrm{~cm}^{-1}$ peak would be due to the defects in $\mathrm{ZnO}$ lattice resulting from the implantation, our Raman studies were extended to two samples of $\mathrm{ZnO}: \mathrm{Mn}$ produced by co-sputtering ( $\mathrm{ZnO}: \mathrm{Mn}(\mathrm{sp})$ ). With this alternative doping method, the extra Raman mode is also present as can be seen in Fig 4b. Moreover, layers co-doped with two 
impurities ( $\mathrm{ZnO}: \mathrm{Al}: \mathrm{Mn}$ ) show essentially the same behavior, as far as the $530 \mathrm{~cm}^{-1}$ mode is concerned, and its relative importance increases with the Mn dose as can be seen in Fig 4c. Thus, we conclude that the extra mode is undoubtedly associated with Mn ions or atoms. As a matter of fact, such an extra mode has been observed before in $\mathrm{ZnO}: \mathrm{Mn}$ doped films [4, 13] and has been interpreted as a local mode due to Mn substituting $\mathrm{Zn}$ in a lattice site [14]. Although such an assignment seems reasonable, the effects of plasmon-phonon coupling, known to be important for GaAs:Mn [15], should be investigated by combining Raman and FIR spectroscopies.

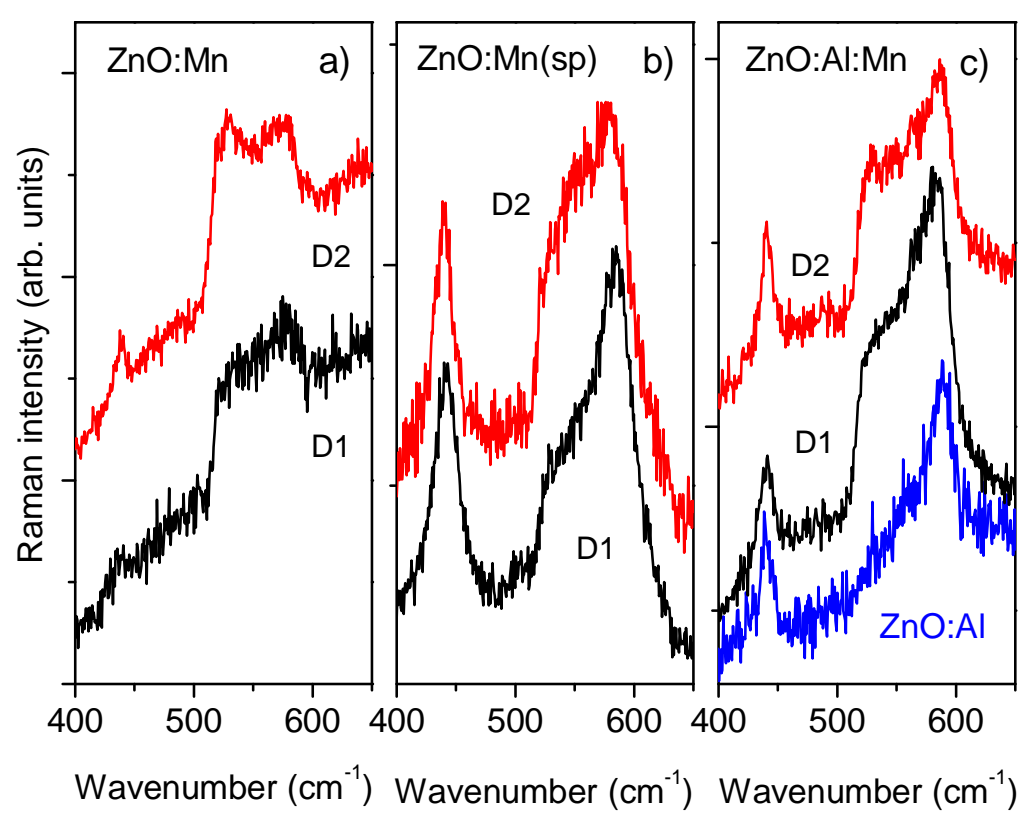

Figure 4: Raman spectra of Mn doped $\mathrm{ZnO}$ films (a), the dose effect in $\mathrm{ZnO}: \mathrm{Mn}$ implanted films; (b) the dose effect in $\mathrm{ZnO}: \mathrm{Mn}(\mathrm{sp})$ films produced by co-sputtering; (c) the dose effect in $\mathrm{ZnO}: \mathrm{Al}: \mathrm{Mn}$ films where also shown, for comparison, the spectrum of ( $\mathrm{Mn}$ free) $\mathrm{ZnO}: \mathrm{Al}$.

\section{Conclusion}

In conclusion, we have been able to produce polycrystalline transparent doped-ZnO layers by RF sputtering technique. Their doping with $\mathrm{Sb}, \mathrm{Al}$ and $\mathrm{Mn}$ can be achieved by ion implantation and subsequent annealing without spoiling their optical transparency and structural properties. Our studies of the films by means of Raman spectroscopy show that doping with $\mathrm{Al}$ or Sb results in the appearance of an intense and broad band in the spectral region close to the LO phonon frequencies of undoped c$\mathrm{ZnO}$. Together with the previously reported data, the list of different impurities that provoke this effect 
becomes long enough to believe that it has a universal origin, a doping-activated enhancement of the (forbidden) scattering on polar LO phonons through the intra-band Fröhlich mechanism. Doping with Mn induces an extra mode at about $530 \mathrm{~cm}^{-1}$. Although, following the opinion published in the literature, we tentatively assign it to the local mode vibration mode of $\mathrm{Mn}$ in substitution position, further studies are necessary to confirm this assertion.

\section{Acknowledgments}

The authors wish to thank J. Rocha from ITN - Ion Beam Laboratory for the implantations. Financial support from the FCT through project PTDC/FIS/72843/2006 is acknowledged.

\section{References}

[1] C. Bundesmann, N. Ashkenov, M. Schubert, D. Spemann, T. Butz, E. M. Kaidashev, M. Lorenz, and M. Grundmann, Appl. Phys. Lett. 83, 10, 1974 (2003)

[2] C. L. Du, Z. B. Gu, M. H. Lu, J. Wang, S. T. Zhang, J. Zhao, G. X. Cheng, H. Heng and Y. F. Chen, J. Appl. Phys. 99, 123515 (2006)

[3] R. Cusco, E. Alarcon-Llado, J. Ibanez, L. Artus, J. Jimenez, B. Wang and M. J. Callahan, Phys. Rev. B $75,165202(2007)$

[4] J. Alaria, M. Bouloudenine, G. Schmerber, S. Colis, A. Dinia, P. Turek and M. Bernard, J. Appl. Phys. 99, 08M118 (2006)

[5] N. O. Dantas, L. Damigo, Fanyao Qu, J. F. R. Cunha, R. S. Silva, K. L. Miranda, E. C. Vilela, P. P. C. Sartoratto, P. C. Morais, Journal of Non-Crystalline Solids 354, 4827 (2008)

[6] H. F. Liu, S. Tripathy, G. X. Hu, H. Gong, J. Appl. Phys. 105, 5, 053507 (2009)

[7] M. Schumm, M. Koerdel, S. Muller, H. Zutz, C. Ronning, J. Stehr, D. M. Hofmann and J. Geurts, New Journal of Physics, 10, 043004 (2008)

[8] J. Ayres de Campos, T. Viseu, A. G. Rolo, N. P. Barradas, E. Alves, T. de Lacerda-Arôso, and M. F. Cerqueira, J. Nanosci. Nanotechnol. 10, 2620-2623 (2010).

[9] A. I. Savchuk, V. I. Fediv, S. A. Savchuk, and A. Perrone, Superlattices Microstruct. 38, 421 (2005). [10] J. M. Calleja and M. Cardona, Phys. Rev. B 16, 3753 (1977).

[11] Landolt-Börnstein Tables, New Series Vol III/22a, edited by O. Madelung (Springer, 1986).

[12] A. G. Rolo and M. I. Vasilevskiy, J. Raman Spectrosc. 38, 618 (2007).

[13] L. W. Yang, X. I. Wu, G. S. Huang, T. Qiu, and Y. M. Yang, J. Appl. Phys. 97, 014308 (2005). 
[14] P. Lakshmi and K. Ramachandran, Radiat. Eff. Defects Solids 161, 365 (2006).

[15] W. Limmer, M. Glunk, S. Mascheck, A. Koeder, D. Klarer, W. Schoch, K. Thonke, R. Sauer, A. Waag et al, Phys. Rev. B 66, 205209 (2002). 